\title{
Article
}

\section{Examining the perceived value of professional judgment and decision making in mountain leaders in the UK: A mixed-methods investigation}

Collins, L., Carson, H.J., Amos, P., and Collins, D.

Available at http://clok.uclan.ac.uk/19882/

Collins, L. ORCID: 0000-0002-7478-1140, Carson, H.J. ORCID: 0000-00023785-606X, Amos, P., and Collins, D. ORCID: 0000-0002-7601-0454 (2018) Examining the perceived value of professional judgment and decision making in mountain leaders in the UK: A mixed-methods investigation. Journal of Adventure Education and Outdoor Learning, 18 (2). pp. 132-147. ISSN 14729679

It is advisable to refer to the publisher's version if you intend to cite from the work. http://dx.doi.org/10.1080/14729679.2017.1378584

For more information about UCLan's research in this area go to http://www.uclan.ac.uk/researchgroups/ and search for <name of research Group>.

For information about Research generally at UCLan please go to http://www.uclan.ac.uk/research/

All outputs in CLoK are protected by Intellectual Property Rights law, including Copyright law. Copyright, IPR and Moral Rights for the works on this site are retained by the individual authors and/or other copyright owners. Terms and conditions for use of this material are defined in the policies page. 
4 Examining the Perceived Value of Professional Judgment and

5 Decision Making in Mountain Leaders in the UK: A Mixed-Methods

6 Investigation

7 Collins, $\mathrm{L}^{1 *}$, Carson, H.J ${ }^{1}$., Amos, $\mathrm{P}^{2}$ and Collins, $\mathrm{D}^{1}$

8

$9{ }^{1}$ Institute for Coaching and Performance, University of Central Lancashire, Preston,

$10 U K ;{ }^{2}$ School of Energy Construction and Environment, Coventry University,

11 Coventry, $U K$

12

13 Loel Collins - Email: LCollins2@uclan.ac.uk, ORCID ID: 0000-0002-7478-1140

14 Howie J. Carson - Email: HCarson1@uclan.ac.uk, Twitter: @ HowieCarson1,

15 ORCID ID: 0000-0002-3785-606X

16 Dave Collins - Email: DJCollins@uclan.ac.uk, Twitter: @ DaveGM4P, ORCID ID:

$17 \quad 0000-0002-7601-0454$

18 Paul Amos - Email: paulamos166@ hotmail.co.uk

19

20

21

$22 *$ Correspondence concerning this article should be addressed to Loel Collins, Institute

23 for Coaching and Performance, University of Central Lancashire, Preston, UK, PR1

24 2HE. Email: lcollins2@uclan.ac.uk. 


\section{Abstract}

This paper utilised a two-part mixed-methodology to examine the value placed on judgement and decision making by a sample of qualified mountain leaders in the UK. Qualified leaders $(N=331)$ completed a web-based survey and a smaller sample $(N=$ 8) were then interviewed. Survey data showed that mountain leaders place greater value on their judgements and decision making when compared to the technical skills of mountain navigation and rope work; however, the process for developing these judgment skills was unclear. Interview data identified that judgment skills appear transferrable from other domains experienced by the leaders (e.g., emergency services, military) but are then recontextualised and modified for effective use within mountain leadership. The leaders facilitated this via a nested reflective process that combines in-action, on-action and on-action/in-context aspects that rely on metacognition. This combination of reflection and metacognition allows for rapid development of judgment making skills in-context. Implications for mountain leadership training are discussed.

Keywords: coach education; expertise; metacognition; reflective practice; survey 


\section{Introduction}

As adventure sports continue to grow in popularity, creating what has been termed 'hard adventure' tourism (Beedie, 2003; Beedie \& Hudson, 2003), UK government policy has focused on the use of the outdoors as a medium to promote health and wellbeing (Sport England, 2015). It has been reported that $48 \%$ of the UK population participate in adventure sport at least once a year (Cousquer \& Beames, 2013; Taylor $\&$ Garratt, 2010). Among these activities and sports, and thus forming the focus of this paper, is mountaineering. Crucially, in response to this increased participation level, the demand for qualified leaders and instructors is clear. As such, this paper addresses the professional characteristics of mountain leaders.

At an organisational level within the UK, Mountain Training UK (hereafter referred to as MTUK) are the governing body that oversees the training of mountain leaders. As part of their role, MTUK administer and certify three different mountain leadership awards (summer, winter and international; see Table 1) to accommodate the mountaineering skills required across various conditions ${ }^{1}$. Notably, each award domain can be characterised as an open, dynamic and, at times, hyper-dynamic environment whereby the task demands are often highly fluid and variable. In summary, award certification requires the trainee leader to have pre-requisite personal and leadership experience within the relevant conditions, attend formal training courses, complete a first aid qualification and to consolidate their personal and leadership skills between training and assessment via ongoing logged evidence of 'quality mountain days' (QMDs) for each award (see Table 1). Overall, training to become a certified mountain leader takes several years of experience and training.

\footnotetext{
${ }^{1}$ IFMG Guides Carnet operates under a standalone scheme and are internationally qualified to operate on glaciated terrain and ski mountaineering.
} 
Regardless of the award being undertaken, assessments are conducted across several days and nights. Indeed, there are distinct advantages to this length of assessment. Firstly, it affords the assessor a better understanding of candidates' expertise over representative timescales (e.g., while on an expedition, in poor conditions). Secondly, it almost inevitably tests candidates' abilities to lead, and adapt, within a dynamic environment that so typically characterises the eventual role. (1)

*** Insert Table 1 near here***

At present, the formalised training programme has an explicit technical focus on the skills associated with mountain leadership, such as; rope work, navigation and camp craft. Application of these declarative technical skills emerges in the experience requirements of the QMDs; that is, by increased 'doing' in practice. It is less clear, however, how the judgment, decision making and leadership skills that are required to be adaptable are actually developed and learnt. An equally essential aspect would also be the assessment of those hyper-dynamic interactions between judgement, decision making and leadership skill that are derived from those experiences (L. Collins, Carson \& Collins, 2016; L. Collins \& Collins, 2015, 2016a). In short, the development towards adaptive expertise. Certainly, judgment and decision making has long been acknowledged as a critical component for successful mountaineering and its leadership. For example, Cousquer and Beames (2013) highlight judgment as a crucial aspect in the professional practice of International Federation of Mountain Guides (IFMG) and International Mountain Leaders (IML). Specifically, from the participant(s) perspective, it is identified that the led participants are passengers in the adventure, 
experiencing a perception of risk without the skills to manage the real risk independently presented by a hazard (Loynes, 1996, Brown, 2000). Fundamentally, the passenger engages a leader to make judgments and decisions about the activity on their behalf. Therefore, it is important that the leader can adequately respond to a changing environment while catering for the adventurous expectations, abilities and safety of the group and individuals within it. Consequently, judgement and decision making skills appear critical for the outdoor leader.

In contrast to the adventure sports coaches identified by L. Collins, Collins and Grecic (2015), and expanding further on the notion of an independent performance, leaders in this context do not seek to develop independent performances in the participant(s). In fact, leaders may actively discourage an independent performance in their clients as part of safety management (ensuring the client behaves in a particular manner in a given situation) or because of a commercial interest (i.e., maintaining return clientele). Accordingly, mountain leaders contribute to the 'experience economy' (Pine \& Gillmore, 1998), delivering the sensations, thrills and experiences sought, but in a manner that can be managed, made safe for and 'collected' (e.g., 'Munroe-bagging' in Scotland) by the participant. Leaders therefore operate to satisfy the requirements and ambitions of their client(s). Because of such activity commodification (Loynes, 1996), the traditional approach of 'apprenticeship' development has been replaced by formalised training, pre-requisite experience and assessments, eventually leading to certification as a mountain leader. In short, the training of leaders may have also become, or at least be perceived as also being, 'commodified'.

In doing so, however, this overlooks a growing realisation that the decision making load on leaders and coaches is high. In part, this is because the participant 
117 has abdicated the complex decisions that are associated with independent

118 participation in favour of a commodified adventure (Loynes, 1996) or collectable

119 experiences and, in another, because of the inherent need to negotiate the

120 nonlinear/complex environment-performer interaction. Within the context of

121 adventure sport coaching, at least, L. Collins and Collins (2015) and D. Collins,

122 Collins and Carson (2016) found preliminary evidence for a nesting of

123 conscious/deliberate (i.e., logical thinking) and intuitive (i.e., gut feeling) decision

124 making processes in order to manage such cognitive loads depending on the

125 situational context and experience.

126 Therefore, the aim of this paper is to understand the relative value placed by

127 UK mountain leaders on judgement and decision making, by considering the nature of 128 those judgements and the manner in which they are developed. In doing so, the paper 129 is presented in two progressive parts; a large-scale web-based survey (Part 1) and 130 semi-structured interviews (Part 2).

131 Part 1

132 Firstly, we sought to assess the level of consensus regarding the value, development 133 and deployment of judgement and decision making in a large sample of qualified 134 mountain leaders via a quantitative online survey.

\section{Method}

136 Participants

137 Participants were 331 qualified mountain leaders $($ male $=287$, female $=44)$. All were

138 at least 18 years of age $\left(M_{\text {age }}=47.1\right.$ years, $\left.S D=11\right)$, as required for mountain

139 leadership accreditation. Ethical approval was provided by the University of Central

140 Lancashire's ethics committee prior to data collection and each participant provided

141 informed consent prior to taking the survey. 


\section{Procedure}

143 A draft survey was constructed using the guidelines outlined by Carson, Collins and

144 MacNamara (2013). This survey consisted of multiple choice ranking and rating

145 questions, as informed by the professional judgement and decision making literature

146 (e.g., Abraham \& Collins, 2011; L. Collins \& Collins, 2016a; Martindale \& Collins,

147 2007). These were then presented to an expert panel for evaluation of effectiveness

148 against the study's aims. These experts, three qualified mountain instructors and an

149 experienced academic within the field of adventure sport, provided feedback and

150 revisions were made to the survey. These revisions were resubmitted for approval to

151 that group before a series of cognitive interviews were conducted (Willis, DeMatio \&

152 Harris-Kojetin, 1999) with a sample of eight representative participants; this step was

153 included to remove any misunderstandings, inconsistencies, inappropriate response

154 options and to expand the process performed by the expert panel. Final revisions

155 were returned to the pilot participants for confirmation and an update provided to the

156 expert panel for their consideration. The survey questions are available online

157 (Supplementary File 1).

158 With the assistance of MTUK acting as a 'gatekeeper', the survey, provided

159 via the online tool Survey Monkey (www.surveymonkey.com), was distributed by e-

160 mail to approximately 4,000 qualified mountain leaders. An explanation of the study

161 aims, purpose and an electronic link to the survey were provided within the e-mail.

162 Progress through the survey was dependent on consent being provided at the start of

163 the survey. Participants that completed the survey were offered the opportunity to

164 enter into a prize draw to win one of three $£ 50$ vouchers as an incentive. All data

165 were anonymised and the termination point for this survey set when stable levels

166 where reached (achieved after $\sim 65 \%$ of completed responses). The survey was 
167 available for completion across a period of 2 months and did not take more than 10

168 minutes to complete.

169 Data Analysis

170 Data were analysed automatically by the website www.surveymonekey.com and

171 presented descriptively in tabulated or graphical form (Figures 1 and 2).

172 Part 1 Results

173 Participants were asked to rank several skills, including decision making, in terms of

174 their importance toward mountain leadership. As shown in Figure 1, decision making

175 was ranked as the highest, closely followed by navigation and the ability to interpret

176 conditions. Contrary to the large emphasis on technical skills within current

177 accreditation courses, mountain leaders rated technical skills (e.g., rope work) as

178 being least important.

179

***Insert Figure 1 here $* * *$

181

At a more specific level (see Table 2), participants expressed strong

183

agreement for the notion that to be effective the mountain leader must exercise good

184 judgment and, that learning from experience is a characteristic of effective mountain

185 leadership. There was overall agreement that developing judgment skill is complex;

186 with a number of participants strongly agreeing. There was greater spread of

187 responses across the options when rating whether errors in judgment are inevitable

188 and that good judgment is a product of poor judgment, therefore challenging the

189 adage that good judgment is learnt from previous experiences of poor judgment.

190 Results suggest that mountain leaders neither agree nor disagree on these statements; 
191 in short, how judgment is developed is unclear to the participating mountain leaders 192 in the study.

It is clear from Figure 2 that participants consider good mountain leadership to more often than not rely on logical thinking rather than the use of gut feeling responses (Figure 2A), and that this generally reflects their professional practice

199 (Figure 2B). Whereas, in scenarios outside of the mountain leadership context, 200 participants reported a lower extent of logical thinking in their decision making 201 process; responses shifted slightly to a more balanced use of gut feeling and logical 202 thinking (Figure 2C). There was little difference between participants' views on their 203 learning contexts, only 11 more participants thought that their learning was carried 204 out informally versus formally with the remainder expressing an even 50/50 split 205 (Figure 2D). This challenges views regarding the value placed on formalised training 206 for coaches and leaders and may be a consequence of the pre-requisite requirement 207 prior to training. Data in Figure 2E suggests that mountain leadership requires a 208 blend of decisions to be made in practice and planned for in advance. Less than $10 \%$ 209 of participants reported a split equal to or higher than 90/10 (or 10/90). Perhaps

210 reflecting the dynamic nature of these leaders' role, there were slightly more

211 responses suggesting that decisions were made more often in practice. Finally, an 212 overwhelming majority of participants categorised their pre-planned decisions as 213 underpinned by logical thinking (Figure 2F). 


\section{Brief Discussion}

218 Data provide support for the notion that decision making is highly valued by

219 mountain leaders. At the very least, this indicates a possible need for greater

220 emphasis on decision training during training and assessment and, that such a

221 modification is likely to be well received/supported by mountain leaders themselves.

222 Although it is apparent that the development of decision making skill is an active,

223 often logically thought through, process that is reliant upon experience, the overall

224 lack of agreement on how it was best developed warrants further investigation. In this

225 regard, data support previous findings (D. Collins et al., 2016) showing that decision

226 making in adventure sport requires a blending of logical thinking and gut feel

227 responses, which may provide a suitable start point for future development. As such,

228 considering the similarly dynamic environment in which mountain leadership

229 operates, it would be surprising if the cognitive demands were not similarly complex.

230 Research to understand the possible mechanisms involved would therefore be a

231 logical extension of this work.

\section{Part 2}

233 Having determined that judgment and decision making are highly valued by mountain

234 leaders, we present a qualitative study to provide a richer and in-depth exploration of

235 the development and utilisation of such judgement and decision making skills.

236 Method

237 Participants

A sample of accredited UK Mountain Leaders $\left(N=8,6\right.$ males, 2 females; $M_{\text {age }}$

$239=48.1$ years, $S D=10.85$ ) were purposively selected based on, a) a willingness to

240 participate as expressed at the end of the survey presented in Part 1, b) current 
241 accreditation as a Mountain Leader (Table 3) and, c) over 5 years of experience post

242 qualification at Summer level. As such, participants also completed the survey prior

243 to interview. Ethical approval was provided by the University of Central Lancashire's

244 [university name removed for blind peer-review purposes] ethics committee prior to

245 data collection and each participant provided signed informed consent.

$* * *$ Insert Table 3 here***

\section{Procedure}

250 Following analysis of survey responses from Part 1, a semi-structured interview guide

251 was constructed with the additional inclusion of questions/probes based on literature-

252 derived themes. The questions drew on critical incident technique (Flanagan, 1954)

253 as a "knowledge elicitation strategy" (Flin, O'Connor \& Crichton, 2008, p. 222).

254 This approach was adopted to uncover any complexities when applying knowledge

255 within the mountain environment. Critical incident technique has been utilised in the

256 past with experienced decision makers, targeting key judgments during nonroutine

257 activities (Crandall, Klein \& Hoffman, 2006; Flin et al., 2008; Hoffman, Crandall \&

258 Shadbolt, 1998). The semi-structured nature of interviews allowed the interviewer to

259 elicit key information and for experiences to be explored in greater depth.

260 Specifically, the process involves a partnership between interviewer and interviewee

261 who select a key incident that can be clearly defined and then examined at a deeper

262 level. The key element is an exploration with the interviewee of what information

263 was influential when changing an assessment of the situation, or when selecting a

264 particular course of action (Flin et al., 2008). 
This interview guide was piloted with six representative participants and

266 feedback was sought regarding the content, structure and procedure. Amendments to

267 the guide were made and then returned to the representative group for confirmation.

268 The interview guide can be found in Supplementary File 2. Interviews were

269 conducted at a convenient time for each participant and in a private location to ensure

270 anonymity. The mean interview duration was 31 minutes and interviews were

271 recorded on an electronic Dictaphone device that stored data in mp3 file format.

\section{Data Analysis}

273 Following the guidance provided by Braun and Clarke (2006), data were analysed

274 using a thematic analysis. Accordingly, interviews were first transcribed verbatim 275 and read several times to fully apprehend the essential features (Sandelowski, 1995).

276 General impressions of these data were written in note form and shared between the 277 researchers conducting the analysis (first and third authors). Secondly, driven by an

278 interest in the decision making processes and its epistemological underpinnings, an

279 initial deductive coding of response data was applied to each transcript; thus formally

280 identifying relevant extracts. Thirdly, data codes were collated into lower-order

281 themes based on common features, which were then grouped together under higher-

282 order themes representing the highest level of abstraction. Within a fourth phase of

283 analysis, these themes were subjected to review and further refinement by the

284 researchers. The primary aim was to check for a shared understanding and

285 interpretation of data and, therefore, the emerging themes as a whole data set. This

286 process involved revisiting the original transcripts, interviewer notes and digital

287 recordings, enabling themes to be reconsidered, combined, broken down and the

288 generation of new themes. Importantly, the development of themes at any point

289 during the analysis did not depend on the prevalence of a code, but rather, on what the 
theme revealed about the decision making process and its philosophical

291 underpinnings.

In addition to the steps outlined above to, the issue of trustworthiness was

293 addressed through use of an additional researcher, who was not involved in the

294 interviewing or coding process, independently coding a random sample of the

295 transcripts (25\%) to ensure inter-coder agreement. Data were coded against the

296 developed themes and assessed for the level of agreement. Three disagreements

297 regarding these differences in codes were discussed until a consensus was reached.

298 Results

299 Initial analysis identified 247 coded units. These were subsequently grouped into 70

300 lower-order, 15 mid-order and 5 higher-order themes (see Table 4). Higher-order

301 themes were then discussed in the context of the second set of research questions;

302 What value do UK mountain leaders place on judgement and decision making and,

303 what are the characteristics of judgment skills in mountain leaders? Higher-order

304 themes emerged during the analysis and formed the structured discussion outlined

305 below. A variety of different length quotes from all the participants have been used to 306 illustrate the points made throughout the discussion.

$$
\text { ***Insert Table } 4 \text { here*** }
$$

\section{Brief Discussion}

\section{Metacognition}

312 Metacognition (L. Collins et al., 2016) emerged as an overarching higher-order theme

313 that links the four other higher-order themes. Data support recent proposals that

314 metacognition forms an important aspect of the decision making process (L. Collins et 
315 al., 2016). It is suggested that metacognition assists the naturalistic 'gut feel' decision

316 making (NDM) processes whilst in-action. Furthermore, metacognition underpins the

317 reflective process associated with maximising the learning from experience. In this

318 respect, the blending of NDM processes and metacognitive attributes enables the leader

319 to manage high cognitive loads associated with the in-action decision (L. Collins \&

320 Collins, 2015). Evidently two aspects emerged from the interviews; firstly, an ability

321 to reflect on the process of the decision and the decision outcome. ML7 highlights a

322 metacognitive capacity as follows, "So I purposefully stopped the group and tell them

323 that I need to make a couple of decisions". As part of this decision to stop, the nature

324 of the decision was reviewed and reflected on, and the consequences of the action and

325 impact on the group was considered as part of the contextual framework for the

326 decision.

327 Secondly, the capacity to anticipate changes in a situation and to accommodate

328 those possible 'new' variables into the leadership decisions as an ongoing auditing

329 process was apparent. Referring specifically to managing risks and illustrating the

330 cognitive load, ML4 explained: Identifying and managing [anticipating] all the risks that are coming up. Even if they're only very slightly apparent. So the changes of weather, changes in the physical state of your group are things you need to make an effort to keep tabs on.

It seems likely that those anticipated changes are analogous in nature and draw on previous experiences of similar situations. However those changes may be

337 metaphoric in nature when learning from experiences to inform novel situations or 338 new context.

\section{Diverse mental models}


340 During planning processes, the mountain leader utilises predominantly a classical

341 'logical thinking' decision making (CDM) style (cf. L. Collins \& Collins, 2016b, in

342 adventure sport). Following sufficient volume of experience, the leader is able to

343 anticipate, prioritise and plan for potential courses of action within specific contexts

344 (i.e., the likelihood of implementing alternative plans). Moreover, these actions

345 appear to be stored as a procedural chunk and highly associated with recognisable

346 contextual demands (e.g., the clearly delineated Danger, Response, Airways,

347 Breathing, Circulation [DRABC] procedure in First Aid situations). For example,

348 ML1 described: "So I gave them [the lost walkers] my spare clothes to warm them up

349 a bit. I always bring spare clothing" that are carried as a requirement by the mountain

350 leader. ML3 highlights the valuable impact of such procedures within a more

351 complex context that served to reduce the cognitive load:

So I suppose using my first aid knowledge and the procedures that you learn in basic first aid going through your ABCs etc. [the delineated procedural chunk], actually asking the right questions I could see that [was] more than indigestion and to be honest with you, that was a fairly easy decision.

358 the knowledge within the leader's community of practice, as exemplified by ML8 in

359 the following: "on slopes of this aspect after these conditions I anticipate ' $\mathrm{X}$ '

360 conditions". Without experience of that actual slope, but by drawing on experience

361 of similar slopes (aspect, shape, gradient etc.) in similar conditions, leaders often

362 combine this knowledge with the advice of another leader who has direct experience

363 of the slope in question. 
An interesting aspect of the community of practice is the value placed on the provided information as being equal to the leader's own; in other words, there is a high degree of trust between mountain leaders. With this information, the leader generates a range of mental models/options that relate to a particular sequence of events, pivotal occurrences or combination of factors. This aspect of judgment and decision making is broadly classical in nature and allows the leader to rationalise, prioritise and reduce the range of options considered in-action, essentially narrowing the range of options considered and reducing cognitive demands on the NDM process. ML 8's statement that "But feels like relatively smaller decisions, really. But the big

373 decisions you've made a long time ago" highlights the "big decision as part of the

374 planned process". In this respect, the metacognition facilitates the nesting of CDM and NDM in the judgement and decision making process. This metacognitive capacity appears critical within the professional judgement and decision making

377 (PJDM) approach advocated by Abraham and Collins (2011) and L. Collins et al. 378 (2016) and, as we have demonstrated, is highly valued by these mountain leaders.

379 Like their coaching colleagues, mountain leaders experience high cognitive loads and 380 a strong metacognitive capacity would seem well developed to assist in managing this 381 demand.

\section{Judgment and decision making}

383 As stated earlier, anticipation of particular events, pivotal occurrences or specific 384 combinations of factors prime the leader in 'selecting' from a predetermined set of 385 options. Metacognition allows the generation of heuristics that facilitate a quicker 386 route to an option derived from CDM. This illustrates the nested synergy of NDM 387 and CDM that may operate in the PJDM model. ML 8 describes the classical, logical388 thinking part of the process at a crucial moment in a walking tour: “... you want to be 

there when it's stable [the snow]" and also illustrates the result of actually arriving at that snow slope "... I was listening to my body then, when I realised that, kind of shaking knees means that you should really not be there."

While the crux had been planned for and anticipated, the decision not to cross the slope was based on a more naturalistic, gut feel, process arrived at in-context. ML7 highlighted the on-action/in-context aspects of judgement and decision making identified by L. Collins and Collins (2015), while also anticipating the consequence in context. For instance, the group getting cold while the leader collects information to utilise in an apparently CDM process: "So I purposely stopped the group and tell them that I need to make a couple of decisions, stay here, put a layer on".

The mountain leaders appeared to attribute the in-action process to intuition, with ML1 suggesting that his intuition reflected him knowing he "had The Force with me basically". The leader's ability to rationalise their intuitive decisions appears to contradict such a belief, suggesting that this is not the case and that the term 'intuition' is misused in this context. We do not dispute that intuition forms part of the decision making process (Lufityanto, Donkin \& Pearson, 2016), but suggest that it is overemphasised due to its perceived high value status among leaders and possibly because decision making is articulated from a solely CDM perspective. In short, aspects of decision making that are not classical in nature must, therefore, be intuitive because no other known terms can be applied.

Options that were generated changed in priority as the activity progressed and appear to be conceptualised as a set of loose parts that can be reconfigured to facilitate multiple outcomes in contexts (i.e., "now priorities are XYZ, while at other points the priorities will be ZXY"). This contributes to the high cognitive load attributed within 
414 the decision making process and, once again, links the judgement and decision

415 making process to the overarching/integrating metacognitive theme. The cognitive

416 load is associated with the adaptation, flexibility and creativity of a blueprint plan that

417 utilises preselected components, rather than constructing completely novel procedures

418 in the field. Action plan components are selected based upon their capacity to be

419 integrated. As such, appreciation of the context, situational awareness and demands is

420 highly significant to the decision making process.

421 Contextual framework

422 Judgment and decision making skill facilitates the adaptability and flexibility required

423 when utilising the loose parts, mentioned earlier, in a range of different

424 configurations. This facilitating mechanism and associated metacognitive processes

425 operate within a contextual framework that acts as scaffolding for the decisions.

426 Consideration towards the environment, group, and their interaction is similar to the

427 situational awareness described by Endsley and Garland (2000) and Banbury and

428 Tremblay (2004). ML2 explains:

We were quite a way down, you know. Actually, if the weather had been better, we'd have had different options...you know, to go high up in the Cairngorms. So if the weather had changed then we would have had different options.

Fixed parameters, such as group experience, size and nature, terrain, gradient

435 and a limited range of anticipated or planned possibilities (e.g., task, conditions) act as 436 scaffold supports for the judgements and decisions. This declarative knowledge 437 demonstrates a deep understanding of the contextual framework. The contextual 438 framework constrains the decision in practice. This extends the concept of situational 

awareness (Flin et al., 2008) and Abraham and Collins' (2011) situational demands to encompass a greater 'projection of future state' than either description implies, however does require further research. Indeed, this 'anticipated state' is influenced by the practicality of the leader's decision, with the decision itself having an impact on the future state, as ML1 explains: "if I do X I need only consider Y and Z as possible alternatives". ML5 also illustrates the point clearly: and to be quite forthright, people saying 'right well if you don't reach this point by this time that's it we're turning round because if you go on you will then go over the time limit and you will be slower coming down'. The delay by proceeding resulting in the need to cross a snow slope that will be exposed to the sun and consequently more avalanche prone. In not reaching a particular point on an ascent, the leader knows that the original plan is unachievable. In knowing that the ascent from a given point (e.g., a col) to the summit will take 2 hours, by not reaching that point with 2 hours to spare the final summit ascent becomes impossible. This appears to be facilitated by the predetermined options derived from the plan and supports identified earlier. In addition to the standard operating procedures, specific mental models for action are generated via the planning process. These models draw on the experience and declarative, technical and nontechnical knowledge/skills of the mountain leader. These constructed models are specific to the context of the proposed activity (dependant on the contextual frame) and operate alongside the standardised, more routine, procedures. In this respect, the number of options available to the leaders in a given situation is reduced into a manageable load. Such preplanned options appear to reduce the leader's cognitive load in a given situation, selecting from a predetermined 
463 short-list of options or tools available and, therefore, enabling the leader to be flexible

464 and adaptive within the constructed contextual framework.

465 Declarative technical skills including rope-work and navigation are taught

466 during training. Additionally, a range of nontechnical skills such as judgement and

467 decision making that are associated with leadership, emerge from the reflective

468 processes of the leader's own experiences or from previous formalised training (e.g.,

469 military, emergency services, police, business). In reality, the development of these

470 nontechnical skills is frequently a combination of the two. ML2 described a

471 particular course of action towards the summit of a mountain walk, "we're commando

472 forces so it was.... Nobody gets left behind". ML6 draws on their experience within a

473 military, paramedic role and states:

474 I learnt a lot of decision making and being a leader through the

475 military....Leadership skills, teamwork skills was driven by that more than

476 when I did my Mountain Leadership training.

In addition, ML6 also states “there's lots talked about reflective practice

479 within my paramedic role". These nontechnical skills appear to be reconceptualised

480 from other sources or developed via reflective and metacognitive skills. Importantly,

481 both approaches to the development of judgement require the metacognitive capacity

482 highlighted earlier. The first as part of the reflective process associated with learning

483 from experience, the latter in the transfer of skills to new domains or contexts. It

484 seems most likely that the two are interrelated and operate in synergy. Further

485 examination of this complex process is worthy of further investigation.

\section{General discussion}


487 The aim of this paper was to understand the relative value placed by UK mountain

488 leaders on judgement and decision making, by considering the nature of those

489 judgements and the manner in which they are developed. In doing so, the paper

490 addressed two questions: What value do UK mountain leaders place on judgement

491 and decision making and, how are these judgment skills learnt, developed and

492 refined?

What value do UK mountain leaders place on judgement and decision making?

494 Mountain leaders clearly value judgement and decision making skill, as evidenced by

495 its top ranking position (above procedural technical skills) in the survey and important

496 impact offered within the interviews. Indeed, results revealed an important

497 recognition for practical integration of technical, leadership and judgment skills in a

498 synergy for optimum effect. Despite its highly assigned value, however, decision

499 making appears not to be explicitly taught during the mountain leadership training in

500 the UK; at least not according to the in-depth interviews in Part 2. In our professional

501 experience this is, likewise, generally common amongst other, more traditional, sports

502 coaching qualifications. This deficit could be seen to represent misalignment between

503 training and practice. Such perspectives are, however, in line with the PJDM

504 approach that similarly places an emphasis on judgment and decision making because

505 of its acknowledgment that leadership is complex, thus requiring adaptability and

506 flexibility. Recent studies have recommended that training/assessment be more

507 aligned with practice, with the need for a mixed assessment of both declarative

508 technical skill and decision making (particularly in higher awards: L. Collins et al.,

509 2016). Looking to the future, important questions for mountaineering training bodies

510 are, therefore, what does it mean to be a mountain leader? What are the essential

511 skills required by mountain leaders? 
How are these judgment skills learnt, developed and refined?

513 There were two main mechanisms that leaders in this study suggested for how they

514 were able to improve their judgment and decision making skills in their own practice.

515 Expressly, transferred leadership and decision making skills from either other

516 formalised training (e.g., emergency services or military) or via a process of

517 experience and self-directed reflection were identified. The former required leaders

518 to recontextualise existing knowledge and skills, or the reconstruction of that

519 knowledge and skill, both however require quality practical experience as a mountain

520 leader, reflective and metacognitive capacity. The processes of experiential learning,

521 however, are not facilitated in the mountain leader training. As a result learning from

522 the QMds is potentially ad-hoc in nature, relying on reflective skills that are, also,

523 learnt and transferred from other contexts. In practice, this reflection on experiences

524 is associated with an intention to act (Martindale \& Collins, 2005) that relates to the

525 goal associated with that judgement and is constrained by the contextual framework.

526 With the QMDs already required by MTUK as part of the formalised training,

527 it would seem sensible to capitalise on leaders' ability to learn from such experiences.

528 Accordingly, integrating metacognitive training (e.g., cognitive apprenticeship or

529 decision training) alongside declarative technical and nontechnical skills, with a clear

530 contextual framework that includes prioritised mental models, is an obvious way

531 forward for future training. Indeed, this might require the leader to articulate their

532 decision making and explain how it was derived. Crucially, such a requirement must

533 be understood, bought into and valued by the trainee leaders and, finally, supported

534 and reinforced by the community of practice.

\section{Conclusion}


536 In conclusion, there is much potential for research and development in judgement and

537 decision making skills for mountain leadership. This study has identified that

538 mountain leaders highly value these skills but are unsupported in knowing how to best

539 develop them. We have explained that the existing training structure is advantageous

540 for several reasons, including the duration, scope and practical requirements.

541 However, we propose that, without formal support for developing good judgment and

542 decision making skills, potential leaders are at a disadvantage when presenting for

543 assessment. In short, greater efforts need to be directed towards maximising the QMD

544 experiences which, in turn, we suggest will upskill the leadership workforce to

545 support the UK's growing industry in the wake of recent health initiatives. 


\section{References}

Abraham, A. \& Collins, D. (2011). Taking the next step: Ways forward for coaching science. Quest, 63, 366-384. doi:10.1080/00336297.2011.10483687

Banbury, S. \& Tremblay, S. (2004). A cognitive approach to situation awareness: Theory and application. Abingdon: Routledge.

Beedie, P. (2003). Mountain guiding and adventure tourism: Reflections on the choreography of the experience. Leisure Studies, 22, 147-167. doi:10.1080/026143603200068991

Beedie, P. \& Hudson, S. (2003). Sport and adventure tourism. New York: The Haworth Press, Inc.

Braun, V. \& Clarke, V. (2006). Using thematic analysis in psychology. Qualitative Research in Psychology, 3, 77-101. doi:10.1191/1478088706qp063oa

Carson, H. J., Collins, D. \& MacNamara, Á. (2013). Systems for technical refinement in experienced performers: The case from expert-level golf. International Journal of Golf Science, 2, 65-85. doi:10.1123/ijgs.2.1.65

Collins, D., Collins, L. \& Carson, H. J. (2016). "If it feels right, do it": Intuitive decision making in a sample of high-level sport coaches. Frontiers in Psychology, 7, 504. doi:10.3389/fpsyg.2016.00504

Collins, L., Carson, H. J. \& Collins, D. (2016). Metacognition and professional judgment and decision making in coaching: Importance, application and evaluation. International Sport Coaching Journal, 3, 335-361. doi:10.1123/iscj.2016-0037

Collins, L. \& Collins, D. (2015). Integration of professional judgement and decisionmaking in high-level adventure sports coaching practice. Journal of Sports Sciences, 33, 622-633. doi:10.1080/02640414.2014.953980 
572 Collins, L. \& Collins, D. (2016a). Professional judgement and decision-making in adventure sports coaching: The role of interaction. Journal of Sports Sciences, 34, 1231-1239. doi:10.1080/02640414.2015.1105379

Collins, L. \& Collins, D. (2016b). Professional judgement and decision making in the planning process of high level adventure sports coaching practice. Journal of Adventure Education and Outdoor Learning, 16, 256-268. doi:10.1080/14729679.2016.1162182

Collins, L., Collins, D. \& Grecic, D. (2015). The epistemological chain in high-level adventure sports coaches. Journal of Adventure Education and Outdoor Learning, 15, 224-238. doi:10.1080/14729679.2014.950592

Cousquer, G. O. \& Beames, S. (2013). Professionalism in mountain tourism and the claims to professional status of the International Mountain Leader. Journal of Sport Tourism, 18, 185-215. doi:10.1080/14775085.2014.904246

Crandall, B., Klein, G. A. \& Hoffman, R. R. (2006). Working minds: A practitioner's guide to cognitive task analysis. London: Bradford Book.

Endsley, M. R. \& Garland, D. J. (Eds.). (2000). Situation awareness: Analysis and measurement. London: CRC Press.

Flanagan, J. C. (1954). The critical incident technique. Psychological Bulletin, 51, 327-358. doi:10.1037/h0061470

Flin, R., O’Connor, P. \& Crichton, M. (2008). Safety at the sharp end: A guide to non-technical skills. Boca Raton, FL: CRC Press.

Hoffman, R. R., Crandall, B. \& Shadbolt, N. (1998). Use of the critical decision method to elicit expert knowledge: A case study in the methodology of cognitive task analysis. Human Factors: The Journal of the Human Factors and Ergonomics Society, 40, 254-276. doi:10.1518/001872098779480442 
597 Lufityanto, G., Donkin, C. \& Pearson, J. (2016). Measuring intuition: Nonconscious emotional information boosts decision accuracy and confidence. Psychological Science, Advance online publication. doi:10.1177/0956797616629403

601 Martindale, A. \& Collins, D. (2005). Professional judgment and decision making: The 602 role of intention for impact. The Sport Psychologist, 19, 303-317

603 Martindale, A. \& Collins, D. (2007). Enhancing the evaluation of effectiveness with 604 professional judgment and decision making. The Sport Psychologist, 21, 458474. doi:10.1123/tsp.21.4.458

606 Sandelowski, M. (1995). Qualitative analysis: What it is and how to begin. Research 607 in Nursing and Health, 18, 371-375. doi:10.1002/nur.4770180411

608 Taylor, B. \& Garratt, D. (2010). The professionalisation of sports coaching: Relations of power, resistance and compliance. Sport, Education and Society, 15, 121139. doi:10.1080/13573320903461103

611 Willis, G. B., DeMatio, T. J. \& Harris-Kojetin, B. (1999). Is the bandwagon headed to the methodological Promised Land? Evaluating the validity of cognitive interviews. In M. G. Sirken, D. J. Hermann, S. Schechter, N. Schwarz, J. M. Tanur, \& R. Tourangeau (Eds.), Cognition and research (pp. 133-153). New York: Wiley. 
618 Figure 1. Ranking of skills (1 being the highest and 10 the lowest) in terms of their

619 importance to mountain leadership.

620 Figure 2. Bar charts showing the extent to which participants believed good mountain

621 leadership is dependent on gut feeling or logical thinking (A), their mountain

622 leadership is dependent on gut feeling or logical thinking (B), decisions outside of

623 mountain leadership scenarios are based on gut feeling or logical thinking (C), their

624 mountain leadership decisions are developed informally or formally (D), their

625 mountain leadership decisions are planned in advance or responsive in practice (E),

626 and their planning decisions (prior to the activity) are based on gut feeling or logical

627 thinking $(\mathrm{F})$. 
Table 1.

\begin{tabular}{|c|c|c|c|c|}
\hline Qualification \& Remit & Training Pre-requisites & Training content & $\begin{array}{l}\text { Consolidation } \\
\text { requirements }\end{array}$ & $\begin{array}{l}\text { Assessment } \\
\text { requirements }\end{array}$ \\
\hline $\begin{array}{l}\text { Summer Mountain } \\
\text { Leader }\end{array}$ & $\begin{array}{l}\text { Minimum age of } 18 \text { years. } \\
\text { Minimum experience of } 1 \\
\text { year in hill walking. }\end{array}$ & $\begin{array}{l}\text { Duration }=6 \text { days. } \\
\text { Group management }\end{array}$ & $\begin{array}{l}\text { The period between } \\
\text { training and assessment } \\
\text { varies in length for each }\end{array}$ & $\begin{array}{l}\text { Duration = } 5 \text { days } \\
\text { (including a two night } \\
\text { expedition). }\end{array}$ \\
\hline $\begin{array}{l}\text { The scheme is intended } \\
\text { for those leading groups } \\
\text { in mountainous or remote } \\
\text { country in the UK. The } \\
\text { term 'summer' is used to } \\
\text { describe any conditions } \\
\text { not covered by winter. }\end{array}$ & $\begin{array}{l}\text { Registration onto the } \\
\text { scheme. } \\
\text { Recorded a minimum of } \\
20 \text { QMDs. }\end{array}$ & $\begin{array}{l}\text { Navigation } \\
\text { Access and the } \\
\text { environment } \\
\text { Hazards (including steep } \\
\text { ground and rivers) and } \\
\text { emergency procedures } \\
\text { Equipment } \\
\text { Expedition skills } \\
\text { Weather } \\
\text { Background knowledge }\end{array}$ & $\begin{array}{l}\text { person and is an } \\
\text { opportunity for candidates } \\
\text { to develop skills, paying } \\
\text { particular attention to any } \\
\text { weaknesses identified } \\
\text { during the training course. }\end{array}$ & $\begin{array}{l}\text { Attend a Mountain Leader } \\
\text { training course. } \\
\text { Be familiar with the } \\
\text { syllabus. } \\
\text { Minimum of } 40 \text { logged } \\
\text { QMDs. } \\
\text { Hold a current first aid } \\
\text { certificate, minimum } 16 \\
\text { hours. } \\
\text { Logged at least eight } \\
\text { nights camping, including } \\
\text { at least four nights of wild } \\
\text { camping. }\end{array}$ \\
\hline $\begin{array}{l}\text { Winter Mountain } \\
\text { Leader } \\
\text { Winter can be defined as } \\
\text { the time when snow and } \\
\text { ice prevail or are forecast }\end{array}$ & $\begin{array}{l}\text { Hold the Summer } \\
\text { Mountain Leader award. } \\
\text { Current experience of } \\
\text { hillwalking and } \\
\text { mountaineering in winter } \\
\text { conditions in at least three }\end{array}$ & $\begin{array}{l}\text { Duration = } 6 \text { days. } \\
\text { Leadership and journey } \\
\text { skills } \\
\text { Navigation } \\
\text { Snow and avalanches }\end{array}$ & $\begin{array}{l}\text { The period between } \\
\text { training and assessment } \\
\text { varies for each person. } \\
\text { The exact nature depends } \\
\text { on the weaknesses }\end{array}$ & $\begin{array}{l}\text { Duration }=5 \text { days } \\
\text { (including a two night } \\
\text { expedition). } \\
\text { Attended a Winter } \\
\text { Mountain Leader training }\end{array}$ \\
\hline
\end{tabular}


and is not to be defined by a portion of the year. different UK mountain locations.

Be well practised in the personal use of ice axe and crampons.

Recorded a minimum of 20 Winter QMDs.

\section{International Mountain Leader}

Ice axe and crampon skills identified during the Security on steep ground

Emergency snow shelters and holes

Cold weather injuries

Winter weather

Duration $=$ two 5 day training courses (summer and winter)

Recorded a minimum of 20 International summer QMDs and 20 winter QMDs (UK or overseas) Referee to endorse their experience.

The mountain

environment

International legal and

\section{training course.}

10 Grade I climbs, or equivalent mountaineering routes.

The period between training and assessment varies depending on the weaknesses identified during the training courses. Mountain Training UK encourage candidates to develop experience post training. course (or have been granted exemption). Be familiar with the syllabus.

Minimum of 40 logged Winter QMDs.

Hold a current first aid certificate.

Duration $=9$ days $(4$ summer and 5 winter)

Summer Assessment:

economic situation

Group management and leaders responsibilities

Teaching

Anatomy and physiology

Physical ability

Navigation

Weather

Security

Emergency procedures

Bivouac and survival

skills
Attend an IML Summer

training course.

Be familiar with the

syllabus.

Pass the Speed Navigation

Test.

Hold a current first aid

certificate.

Experience since completing the IML

Summer training.

Winter Assessment: 
Expeditions

Snow-covered terrain
Pass the IML Summer assessment

Complete IML Winter training

Be familiar with the

syllabus

Hold a current first aid certificate, minimum 16 hours.

Minimum of 60 logged QMDs.

Table 2. Ratings about Professional Judgment in Mountain Leadership.

\begin{tabular}{|c|c|c|c|c|c|c|}
\hline & $\begin{array}{l}\text { Strongly } \\
\text { Agree }\end{array}$ & Agree & $\begin{array}{l}\text { Neither Agree Nor } \\
\text { Disagree }\end{array}$ & Disagree & $\begin{array}{l}\text { Strongly } \\
\text { Disagree }\end{array}$ & Average Rating \\
\hline $\begin{array}{l}\text { Effective mountain leadership relies on } \\
\text { good judgement skills }\end{array}$ & 276 & 51 & 1 & 2 & 1 & $\begin{array}{c}1.19 \\
\text { (Strongly Agree) }\end{array}$ \\
\hline $\begin{array}{l}\text { An effective mountain leader has the ability } \\
\text { to learn from experience }\end{array}$ & 272 & 52 & 4 & 3 & 0 & $\begin{array}{c}1.21 \\
\text { (Strongly Agree) }\end{array}$ \\
\hline $\begin{array}{l}\text { Good judgement is a product of poor } \\
\text { judgement }\end{array}$ & 6 & 75 & 112 & 106 & 32 & $\begin{array}{c}3.25 \\
\text { (Neither Agree nor } \\
\text { Disagree) }\end{array}$ \\
\hline Errors in judgement are inevitable & 27 & 173 & 67 & 51 & 13 & 2.55 \\
\hline
\end{tabular}


(Neither Agree nor Disagree)

Developing judgement skill is a complex

Table 3. Participant Qualifications

\begin{tabular}{cc}
\hline Participant No. & Qualification(s) \\
\hline 1 & Summer Mountain Leader \\
3 & Summer Mountain Leader \\
& $\begin{array}{c}\text { Summer Mountain Leader } \\
\text { Winter Mountain Leader } \\
\text { International Mountain Leader }\end{array}$ \\
4 & Summer Mountain Leader \\
5 & $\begin{array}{c}\text { Summer Mountain Leader } \\
\text { International Mountain Leader }\end{array}$ \\
6 & Summer Mountain Leader \\
7 & Summer Mountain Leader \\
& Winter Mountain Leader \\
& Summer Mountain Leader \\
& Winter Mountain Leader \\
\hline
\end{tabular}


635 Table 4. Organisation of Data Codes from the Thematic Analysis.

\begin{tabular}{|c|c|c|}
\hline Higher-order Themes & Mid-order Themes & Lower-order Themes \\
\hline \multirow[t]{3}{*}{ Metacognition } & Anticipation of change & $\begin{array}{l}\text { Conditions (e.g., terrain, } \\
\text { weather) } \\
\text { Environment } \\
\text { Group } \\
\text { Goal (link to plan B) }\end{array}$ \\
\hline & Cognitive load & $\begin{array}{l}\text { High } \\
\text { Changing (i.e., across a day) } \\
\text { Varied (i.e., reflecting the } \\
\text { nature of the decision) }\end{array}$ \\
\hline & Knowledge generation & $\begin{array}{l}\text { Knowledge sharing } \\
\text { Community of practice }\end{array}$ \\
\hline Diverse Mental Models & 'What if?' (anticipation) & $\begin{array}{l}\text { Recognising situational cues } \\
\text { Pivotal moments in group } \\
\text { behaviour/skills } \\
\text { Accumulation of minor } \\
\text { occurrences that then } \\
\text { become significant (i.e., } \\
\text { pattern recognition) } \\
\text { Prioritisation of alternative } \\
\text { possibilities }\end{array}$ \\
\hline
\end{tabular}


Attending to realistic

options (e.g., disregarding winter condition hazards in the summer)

Evolution of planning in accordance with anticipated situations

Engagement in the decision making process

Contextual impact on DM 'span of control' management

\section{Creativity}

Adaptability

Flexibility

Pre-action planning

Classical decision making Naturalistic decision making Recognition of emotional impact

Synergy of classical and naturalistic decision making Misuse of intuition

Metacognition

Process (i.e., flexible application from own experience and knowledge) Protocols (i.e., derived from best-practice)

Procedures (i.e., options to select from)

Standing orders (i.e., external regulation) 
Judgement and decision making

Reflection

Feedback

Contextual Framework

Situational awareness

Community of practice
Routines (i.e., inflexible

application of constructed

knowledge)

In-action

On-action

On-action/in-context

Reflective feedback

Intention to act

Expectation to learn

Explicit (i.e., requested from

leaders)

Implicit (e.g., body

language, response from

group)

Emotional intelligence

Value

Use

Access

Group characteristics (e.g., size, make up etc.)

Task (outcome, process)

Environment (physical,

social)

Knowledge of conditions

Contextual knowledge 
Contextual impact on group

Contextual impact on task

Anticipated changes

Learning context

Rapport with the group

Technical skills

Nontechnical skills

Transferability
Navigation

Rope work

Snow craft

Emergency skill

Tactics

Supervisory skills

Safety skills

Adaptability

Delegation

Response/capacity to change

Leadership styles

Communication

Empathy

Emotional intelligence

Military

Emergency services

Business

Other life experiences 
$637 \quad$ Figures

638 Figure 1.

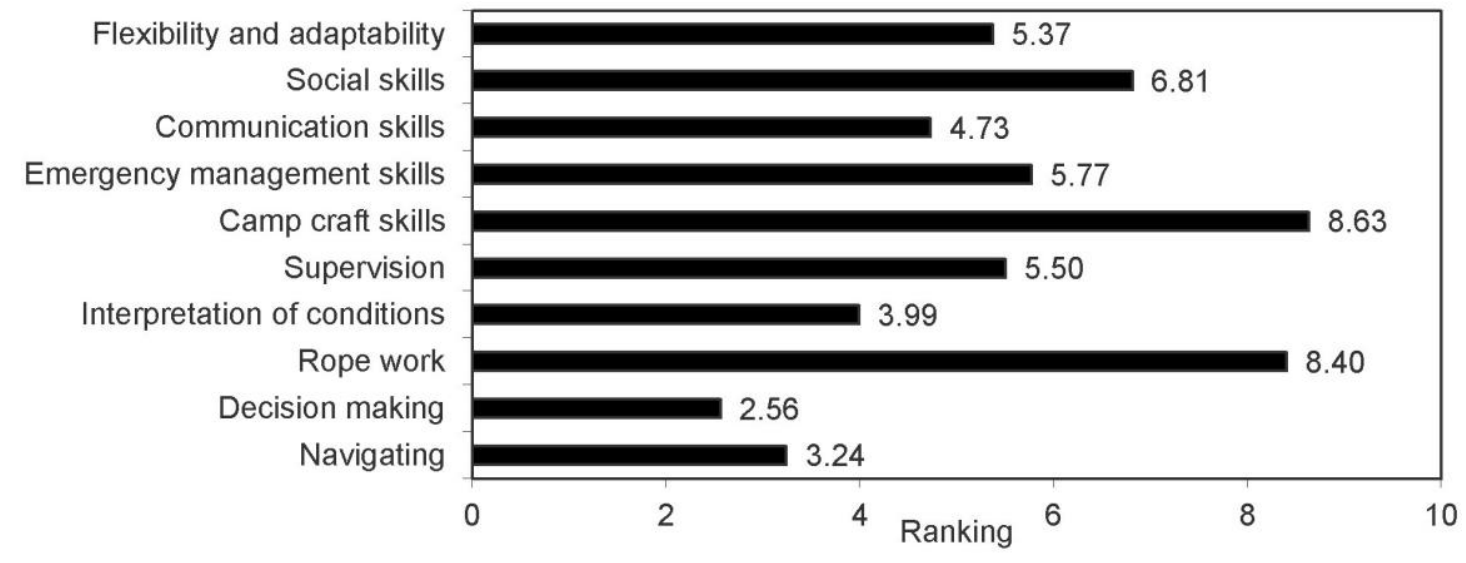

640

641 
Figure 2.
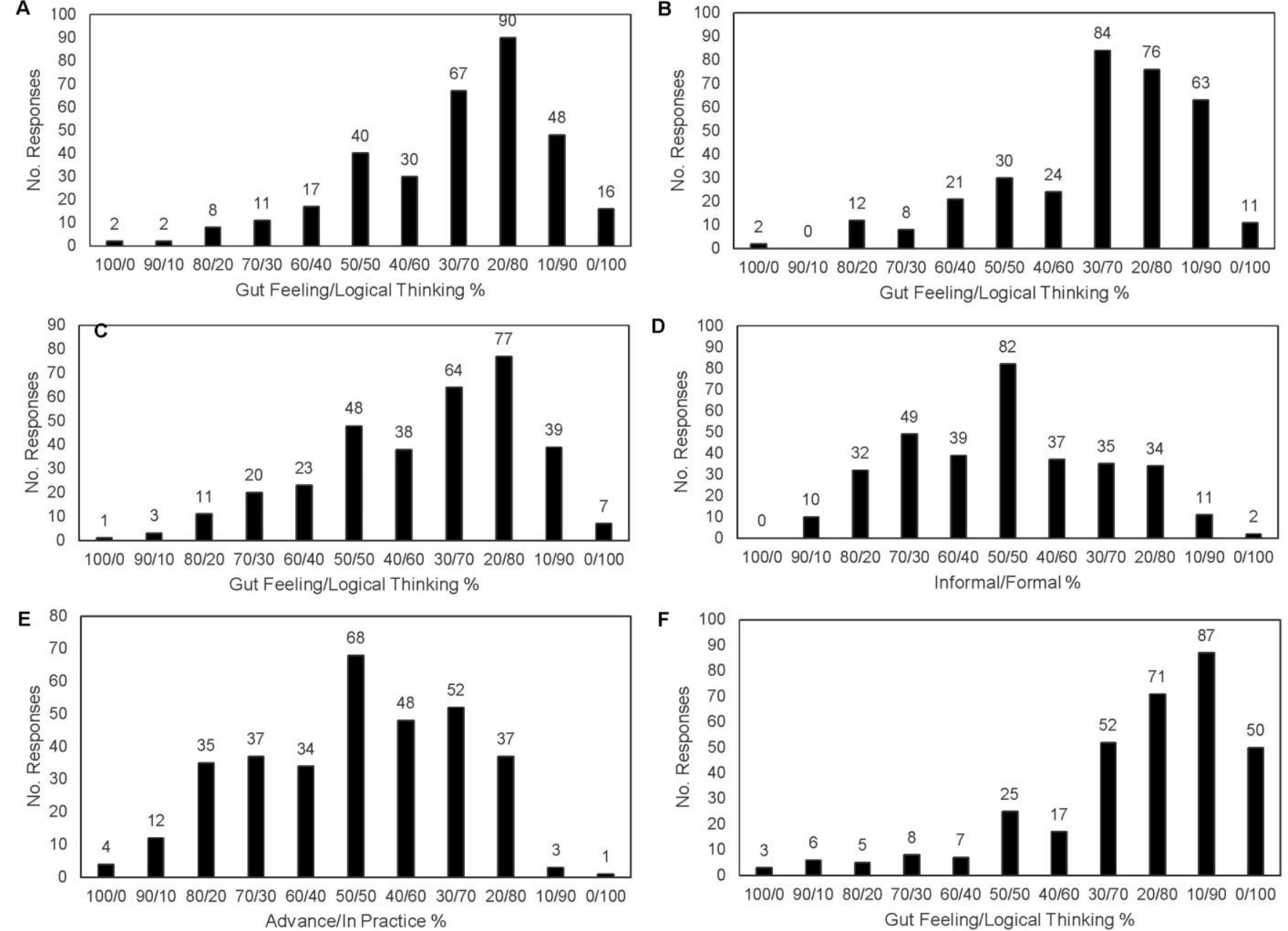